\title{
Nitrogen-doped carbon nanotubes coated with zinc oxide nanoparticles as sulfur encapsulator for high-performance lithium/sulfur batteries
}

\author{
Yan Zhao ${ }^{1}$, Zhengjun Liu ${ }^{1}$, Liancheng Sun ${ }^{1}$, Yongguang Zhang ${ }^{* 1}$, Yuting Feng ${ }^{2}$, \\ Xin Wang ${ }^{*}$, Indira Kurmanbayeva ${ }^{4}$ and Zhumabay Bakenov ${ }^{4}$
}

\author{
Full Research Paper \\ Address: \\ ${ }^{1}$ School of Materials Science \& Engineering, Research Institute for \\ Energy Equipment Materials, Hebei University of Technology, Tianjin \\ 300130, China, ${ }^{2}$ Synergy Innovation Institute of GDUT, Heyuan, \\ Guangdong Province, China, ${ }^{3}$ International Academy of \\ Optoelectronics at Zhaoqing, South China Normal University, China \\ and ${ }^{4}$ Institute of Batteries LLC, National Laboratory Astana, \\ Nazarbayev University, 53 Kabanbay Batyr Avenue, Astana 010000, \\ Kazakhstan \\ Email: \\ Yongguang Zhang* - yongguangzhang@hebut.edu.cn; Xin Wang* - \\ xin.wang@zq-scnu.org \\ * Corresponding author \\ Keywords: \\ batteries; nanocomposites; sol-gel processes; sulfur; zinc oxide \\ $(\mathrm{ZnO})$ \\ Beilstein J. Nanotechnol. 2018, 9, 1677-1685. \\ doi:10.3762/bjnano.9.159 \\ Received: 29 July 2017 \\ Accepted: 21 May 2018 \\ Published: 06 June 2018 \\ Associate Editor: N. Motta \\ () 2018 Zhao et al.; licensee Beilstein-Institut. \\ License and terms: see end of document.
}

\begin{abstract}
Nitrogen-doped carbon nanotubes coated with zinc oxide nanoparticles (ZnO@NCNT) were prepared via a sol-gel route as sulfur encapsulator for lithium/sulfur ( $\mathrm{Li} / \mathrm{S})$ batteries. The electrochemical properties of the S/ZnO@NCNT composite cathode were evaluated in $\mathrm{Li} / \mathrm{S}$ batteries. It delivered an initial capacity of $1032 \mathrm{mAh} \cdot \mathrm{g}^{-1}$ at a charge/discharge rate of $0.2 \mathrm{C}$ and maintained a reversible capacity of $665 \mathrm{mAh} \cdot \mathrm{g}^{-1}$ after 100 cycles. The coulombic efficiency of the cathode remains unchanged above $99 \%$, showing stable cycling performance. X-ray photoelectron spectroscopy analysis confirmed the formation of $\mathrm{S}-\mathrm{Zn}$ and $\mathrm{S}-\mathrm{O}$ bonds in the composite. This indicates that an enhanced cycling and rate capability of the S/ZnO@NCNT composite could be ascribed to advantages of the ZnO@NCNT matrix. In the composite, the active ZnO-rich surfaces offer a high sulfur-bonding capability and the NCNT core acts as a conductive framework providing pathways for ion and electron transport. The as-prepared S/ZnO@NCNT composite is a promising cathode material for $\mathrm{Li} / \mathrm{S}$ batteries.
\end{abstract}

\section{Introduction}

Due to its high theoretical specific capacity of $1672 \mathrm{mAh} \cdot \mathrm{g}^{-1}$ and energy density of $2600 \mathrm{Wh} \cdot \mathrm{kg}^{-1}$, sulfur has been considered as a promising cathode material for lithium/sulfur $(\mathrm{Li} / \mathrm{S})$ batteries [1]. Additionally, sulfur is naturally abundant, has low cost and is environmentally friendly. But it is not conductive, and it dissolves into the electrolyte in the form of lithium poly- 
sulfides $\left(\mathrm{Li}_{2} \mathrm{~S}_{n}, 4 \leq n \leq 8\right)$ during battery operation [2]. This is one of the major challenges in the commercialization of $\mathrm{Li} / \mathrm{S}$ batteries. To overcome this problem, a rational design of the sulfur-based cathode is required, such as the addition of porous conductive materials that could "attract" or "confine" the $\mathrm{S}$ atoms in the cathode, and, therefore, reduce any losses of S.

As an excellent conductive agent, carbon-based materials, e.g., carbon black, graphene and carbon nanotubes (CNTs), have been widely used in $\mathrm{Li} / \mathrm{S}$ composite cathode materials [3]. In addition, by doping with $\mathrm{N}$ and a precise control of its morphology, these carbon materials can also play an active role in $\mathrm{S}$ confinement [4]. For example, it has been reported that the functional nitrogen groups in N-doped graphene (NG) sheets have a good binding capability for lithium polysulfides, which can greatly enhance the life of Li/S batteries [5]. Another popular strategy to reduce polysulfides from dissolution is using metal oxides, such as $\mathrm{TiO}_{2}$ [6], $\mathrm{ZnO}$ [7], $\mathrm{MnO}_{2}$ [8], and $\mathrm{SiO}_{2}$ [9], as the additives or coating layer in the S-cathode. This is because metal oxides can provide strong binding sites with $\mathrm{S}$ and reduce the shuttling effect [10]. In addition, metal oxides can be easily synthesized in various morphologies, e.g., hollow structures, to "hold" S [11]. Similar to S, metal oxides are, however, not conductive [12]. Therefore, an efficient approach is to use hybrids/composites of carbon materials and metal oxides, as they could provide strong binding sites to sulfur while simultaneously improving the conductivity of the electrode.

We previously reported the synthesis of $\mathrm{ZnO}$ nanoparticles on NCNT as anode material for Li-ion batteries [13], and focused on the effect of NCNT on $\mathrm{ZnO}$ nanoparticles. A high concentration of nucleation sites in NCNT allows $\mathrm{ZnO}$ to uniformly grow on its surface with a small size. Also, NCNT has a higher electrical conductivity due to its additional free electron pairs compared to CNT without nitrogen doping. The ZnO@NCNT composite showed excellent electrochemical properties in lithiumion batteries with a reversible capacity of $664 \mathrm{mAh} \cdot \mathrm{g}^{-1}$ after 100 cycles at a current density of $100 \mathrm{~mA} \cdot \mathrm{g}^{-1}$. Inspired by these results, we decided to use the $\mathrm{ZnO} @ \mathrm{NCNT}$ composite as a part of cathode in Li/S batteries, focusing on the effect of $\mathrm{ZnO} @ \mathrm{NCNT}$ on the absorption of polysulfides.

Accordingly, in this work, we synthesized nanocomposites of zinc oxide-coated nitrogen-doped carbon nanotubes with sulfur ( $\mathrm{S} / \mathrm{ZnO} @ \mathrm{NCNT}$ ). ZnO was chosen because it is cheap, nontoxic and stable $[14,15]$. More importantly, $\mathrm{ZnO}$ demonstrates a strong affinity to polysulfides. In addition, NCNT was used due to its good conductivity and the ability of active nitrogen sites to enhance the electrochemical performances of $\mathrm{Li} / \mathrm{S}$ batteries $[13,16]$. To the best of our knowledge, such uniquely structured S/ZnO@NCNT composites have been rarely reported as cathode material for Li/S battery in the literature. Here, we present a composite S/ZnO@NCNT cathode exhibiting stable performance and its structural and electrochemical analysis and evaluation.

\section{Results and Discussion}

Figure 1 shows the XRD patterns of sulfur, ZnO@NCNT and $\mathrm{S} / \mathrm{ZnO} @ N C N T$ composite. It can be seen that $\mathrm{S}$ is successfully incorporated into the composite. The $\mathrm{ZnO}$ patterns can be assigned to hexagonal wurtzite (JCPDS no. 36-1451). For the patterns of $\mathrm{ZnO} @ \mathrm{NCNT}$ and $\mathrm{S} / \mathrm{ZnO} @ \mathrm{NCNT}$, the peaks at about $31.1^{\circ}, 34.4^{\circ}, 36.3^{\circ}, 47.5^{\circ}, 56.6^{\circ}, 62.8^{\circ}$ and $68^{\circ}$ correspond to $\mathrm{ZnO}$ [17], and the broad peaks at around $23.8^{\circ}$ are associated with NCNT [18]. The size of the $\mathrm{ZnO}$ nanoparticles was calculated based on the (101) peak using the Scherrer equation $[13,19]$ and was found to be around $6.2 \mathrm{~nm}$.

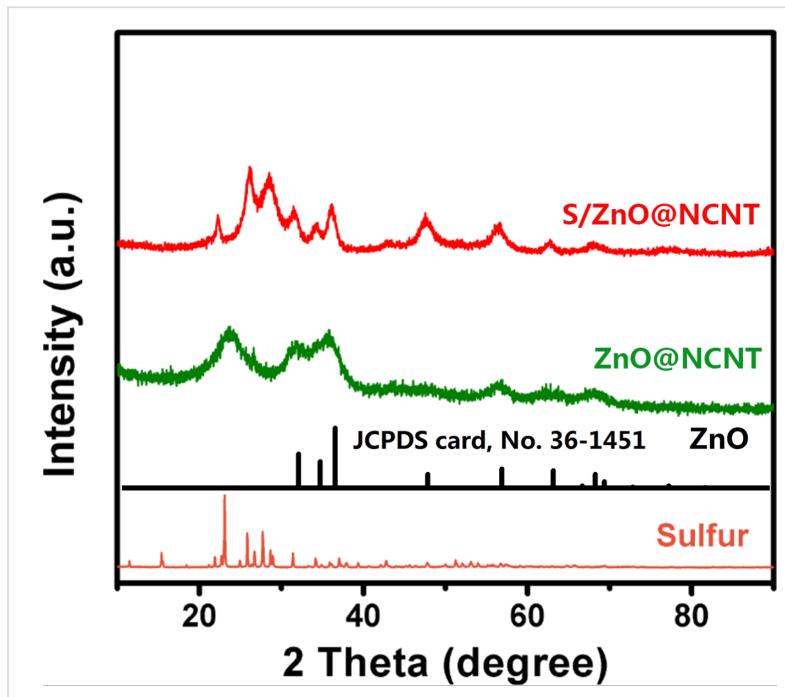

Figure 1: XRD patterns of S, ZnO@NCNT and S/ZnO@NCNT composite.

In order to determine the sulfur content in the S/ZnO@NCNT composite, the samples were studied by thermogravimetric analysis (TGA) in nitrogen gas. Figure 2 shows that the sulfur content in the S/ZnO@NCNT composite is about 74.7 wt \%, which agrees well with the precursors proportions used during preparation. It can be concluded that the adopted technique, ball-milling followed by heat treatment, enables preparation of a high-performance composite of sulfur and $\mathrm{ZnO} @ \mathrm{NCNT}$ as it is shown in the following experiments.

Figure 3 illustrates the morphology and element distribution for the as-obtained $\mathrm{ZnO} @ \mathrm{NCNT}$ composite before S loading. $\mathrm{ZnO} @$ NCNT exhibits a bamboo-like shape, ZnO nanoparticles are uniformly coated on the NCNT walls, and most of the nanoparticles have a diameter of less than $10 \mathrm{~nm}$ (Figure 3c), which 


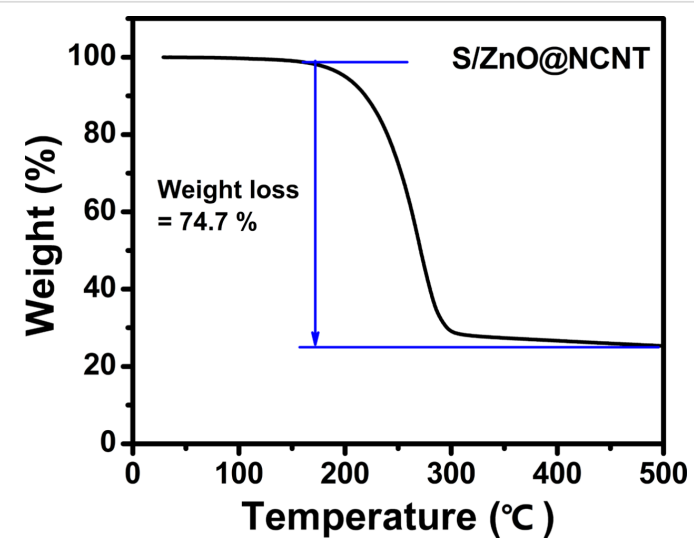

Figure 2: TGA curve of the S/ZnO@NCNT composite.

is consistent with the results of our previous research [13] Energy-dispersive X-ray spectroscopy (EDX) also confirms the presence and even distribution of $\mathrm{C}, \mathrm{Zn}, \mathrm{O}$ and $\mathrm{N}$ in ZnO@NCNT (Figure 3d-g). The crystal lattice fringes with a $d$-spacing of 0.26 and $0.25 \mathrm{~nm}$ were observed in the HRTEM image of the ZnO@NCNT composite (Figure 3a), which correspond to the (002) and (101) planes of $\mathrm{ZnO}$, respectively. Figure $3 \mathrm{~b}$ shows the selected area electron diffraction (SAED) patterns of the $\mathrm{ZnO} @ \mathrm{NCNT}$ composite. The diffraction rings represent different planes of $\mathrm{ZnO}$, revealing the polycrystalline structure of the as-prepared $\mathrm{ZnO} @ \mathrm{NCNT}$. Morphology and structure of the ZnO@NCNT before S loading are similar to those in our previous studies, and were discussed in our previous work [13].

After loading with $\mathrm{S}$, the morphology of resulting S/ZnO@NCNT composite was again characterized by SEM and TEM (Figure 4). These images show that, although there are some large $\mathrm{ZnO}$ particles, the NCNT walls are coated by fine $\mathrm{ZnO}$ particles. Moreover, the EDX mapping confirms the successful loading and homogeneous distribution of $\mathrm{S}$ in the composite (Figure 4f). As can be seen from Figure 4g, the S/ZnO@NCNT composite still maintains a bamboo-shaped structure, but the material is agglomerated and cross-linked to each other, facilitating the transport of ions.

Some of the $\mathrm{ZnO}$ planes in the SAED patterns (Figure 3b), e.g., (101) and (112), are non-polar surfaces. They have been reported to have a much higher surface energy and therefore to be more active than the polar (100) plane [20]. Moreover, the highMiller-index surface (103) observed in SAED pattern is usually more active than a low-Miller-index surface [21]. Therefore, one can expect that these active $\mathrm{ZnO}$ surfaces in the
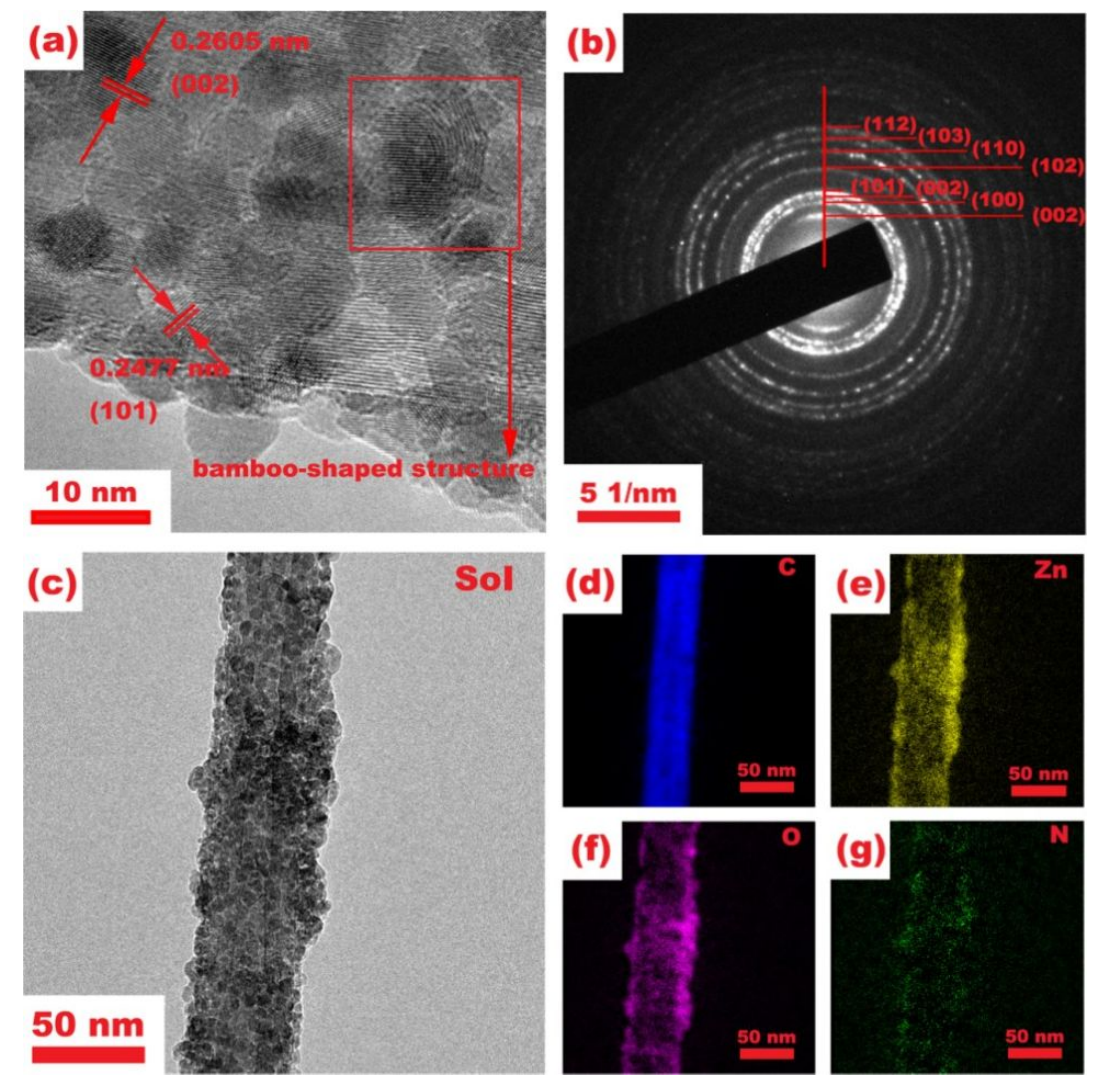

Figure 3: (a) HRTEM image; (b) SAED patterns; (c) TEM image; (d-g) EDX mapping images of the ZnO@NCNT composite. 

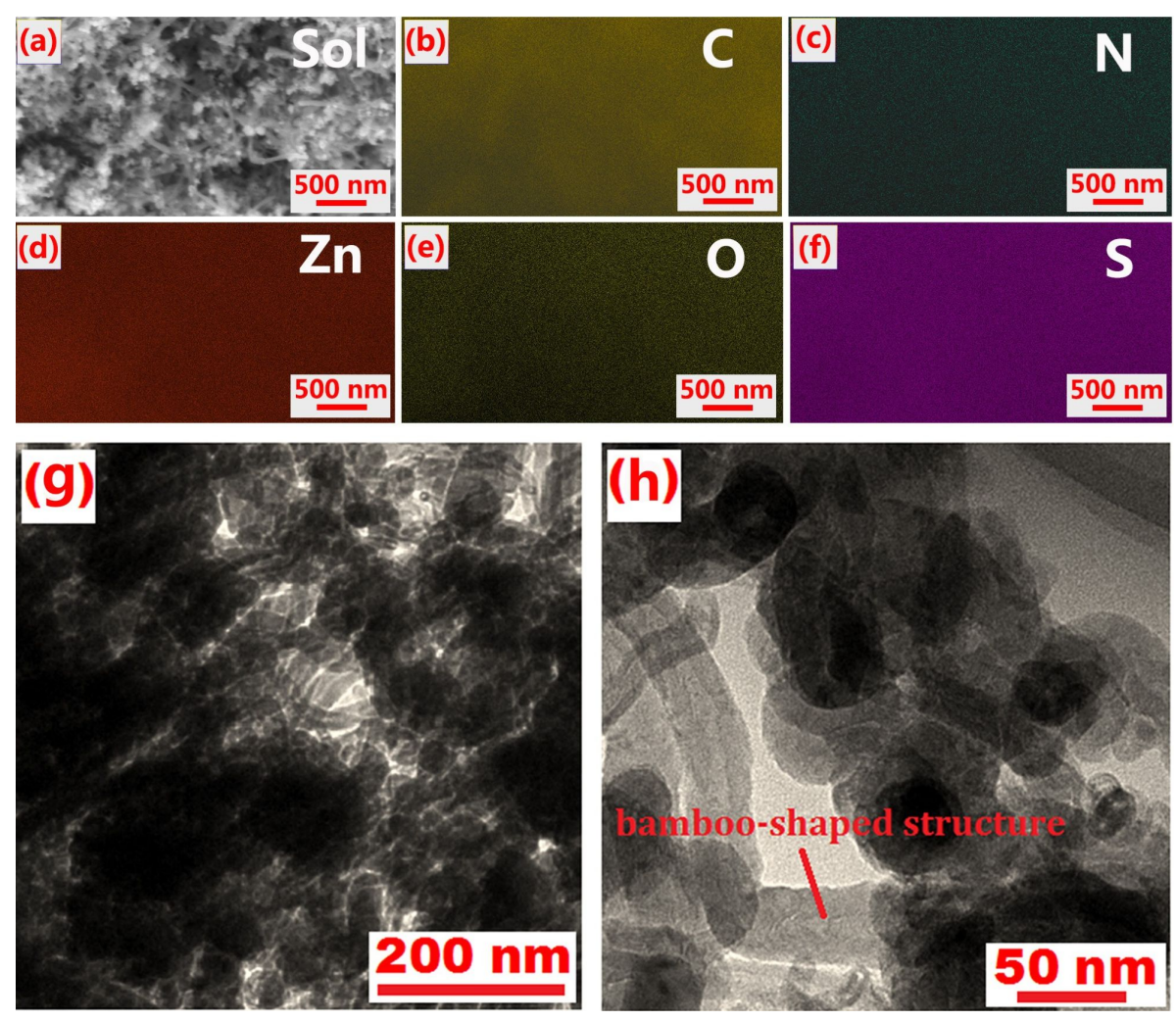

Figure 4: (a) SEM image; (b-f) EDX mapping; (g,h) TEM images of S/ZnO@NCNT composite.

ZnO@NCNT composite can exhibit a strong bonding capacity for $\mathrm{S}$. This will reduce the $\mathrm{S}$ losses to the electrolyte, and thus improve the cycling performance of the $\mathrm{Li} / \mathrm{S}$ battery. In fact, the $\mathrm{S}-\mathrm{Zn}$ and $\mathrm{S}-\mathrm{O}$ bonds were confirmed by $\mathrm{X}$-ray photoelectron spectroscopy (XPS) of the as-obtained S/ZnO@NCNT composite (Figure 5). In the $\mathrm{S} 2 \mathrm{p}$ spectrum, one major peak located at $161.9 \mathrm{eV}$ actually corresponds to the $\mathrm{S} 2 \mathrm{p}$ in $\mathrm{ZnS}$ (Figure 5d) [22]. This suggests that, after S loading, S-Zn bonds were formed. The other two major peaks located at 163.1 and $164.1 \mathrm{eV}$ in the $\mathrm{S} 2 \mathrm{p}$ spectrum could be identified as $\mathrm{S} 2 \mathrm{p}_{3 / 2}$ and $\mathrm{S} 2 \mathrm{p}_{1 / 2}$ species. Moreover, two weak peaks at 163.6 and $165 \mathrm{eV}$ are associated with $\mathrm{S}-\mathrm{O}$ bonds, and another weak peak located around $169.5 \mathrm{eV}$ can be attributed to $\mathrm{S}=\mathrm{O}$ bonds, which might result from $\mathrm{S}$ oxidation or $\mathrm{S}-\mathrm{O}$ bonding on the $\mathrm{ZnO}$ surface [23]. An obvious $\mathrm{C}-\mathrm{N} / \mathrm{C}-\mathrm{S}$ bonding was found at $285.2 \mathrm{eV}$ in the $\mathrm{C} 1 \mathrm{~s}$ spectrum (Figure 5c) [24]. Regarding the Zn 2p spectrum, the peaks located at 1022.2 and $1045.3 \mathrm{eV}$ are the $2 \mathrm{p}_{3 / 2}$ and $2 \mathrm{p}_{1 / 2}$ states, respectively (Figure $5 \mathrm{~b}$ ) [25]. Since $\mathrm{Zn}-\mathrm{O}$ and $\mathrm{Zn}-\mathrm{S}$ have a similar XPS bonding energy in the two $\mathrm{Zn}$ states, they are not distinguishable in the $\mathrm{Zn} 2 \mathrm{p}$ spectrum.

The performance of the as-prepared S/ZnO@NCNT composite as a cathode in $\mathrm{Li} / \mathrm{S}$ batteries was evaluated in lithium half-cell configuration. Figure 6 shows the discharge/charge potential profiles at $0.2 \mathrm{C}$. Two typical plateaus appear during the discharge process. The plateau at $2.35 \mathrm{~V}$ can be related to the formation of long-chain polysulfides $\left(\mathrm{Li}_{2} \mathrm{~S}_{n}, n \geq 4\right)$, another plateau at $2.1 \mathrm{~V}$ is associated with the electrochemical transition of $\mathrm{Li}_{2} \mathrm{~S}_{n}$ to lithium sulfide $\left(\mathrm{Li}_{2} \mathrm{~S}\right)$ [26]. The S/ZnO@NCNT composite delivers an initial specific discharge capacity of $1032 \mathrm{mAh} \cdot \mathrm{g}^{-1}$. There is a slight capacity fading and it drops to $905 \mathrm{mAh} \cdot \mathrm{g}^{-1}$ in the third cycle. The potential plateaus were maintained in the first three cycles.

The cycling performance of the $\mathrm{S} / \mathrm{ZnO} @ \mathrm{NCNT}$ cathode is presented in Figure 7. The results show that after 100 cycles the cathode still maintains a discharge capacity of $665 \mathrm{mAh} \cdot \mathrm{g}^{-1}$. The coulombic efficiency of the S/ZnO@NCNT cathode remains unchanged above $99 \%$ after the 100th cycle, i.e., the S/ZnO@NCNT cathode exhibits very stable cycling performance. The long-term cycling behavior of the S/ZnO@NCNT cathode is presented in Figure 8. One can see that the system exhibits an extremely steady performance even after 300 cycles at $1 \mathrm{C}$.

It is suggested that such a good performance originates from a strong bonding capacity of the reactive $\mathrm{ZnO}$ planes in the com- 

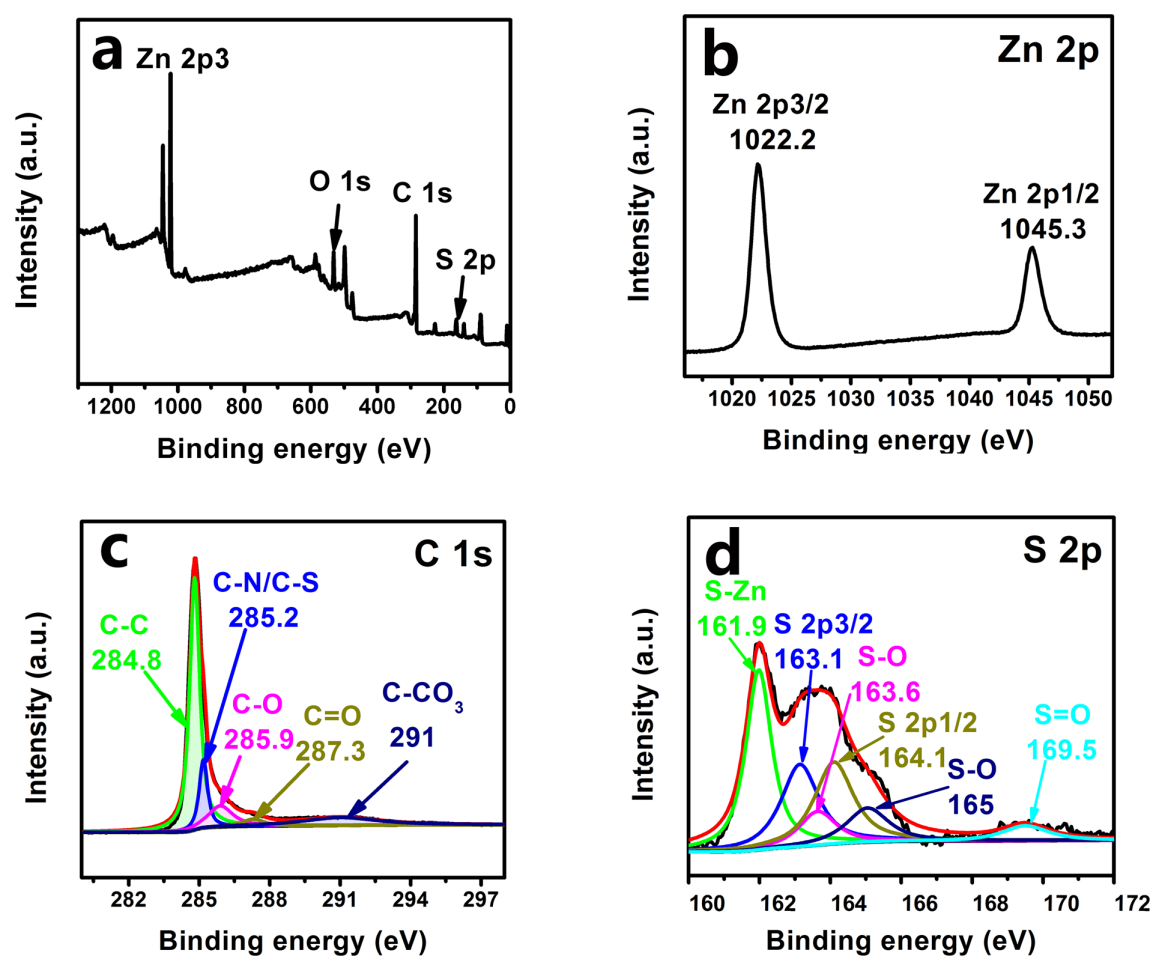

Figure 5: XPS spectra of S/ZnO@NCNT composite.

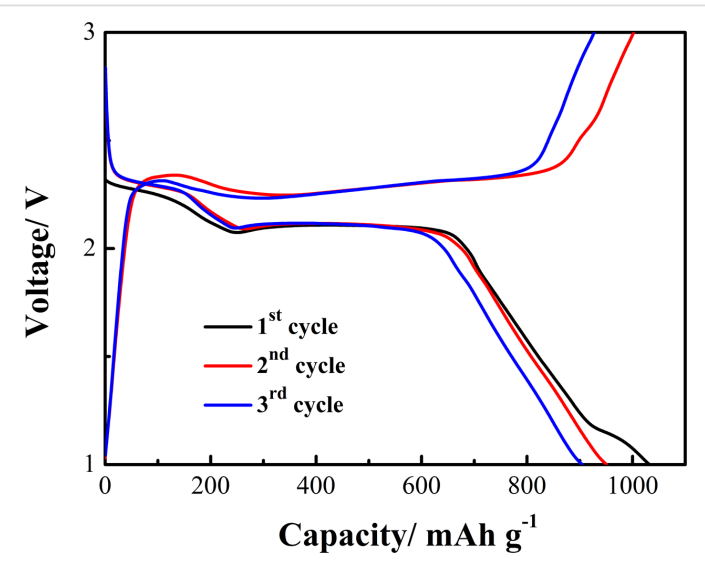

Figure 6: Discharge/charge voltage profiles of the S/ZnO@NCNT cathode for the initial three cycles at $0.2 \mathrm{C}$.

posite. As confirmed by the XPS analysis, the exposed active surfaces on $\mathrm{ZnO}$ can "hold" a large amount of S species through $\mathrm{Zn}-\mathrm{S}$ and $\mathrm{O}-\mathrm{S}$ bonds and therefore contribute to the observed excellent cycling performance.

In a $\mathrm{Li} / \mathrm{S}$ cell, the amount of sulfur loading is critical and strongly influences its electrochemical performance. Therefore, we fabricated $\mathrm{S} / \mathrm{ZnO} @ \mathrm{NCNT}$ electrodes with various S loadings of about 2.50, 3.25, 4.00 and $4.75 \mathrm{mg} \cdot \mathrm{cm}^{-2}$, and investigated the effect of loading on the discharge capacity of the com-

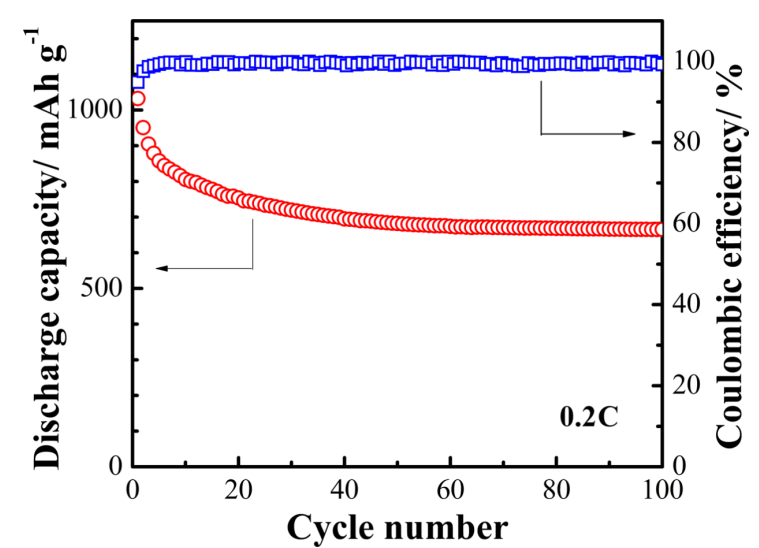

Figure 7: Cycling performance of the S/ZnO@NCNT cathode at $0.2 \mathrm{C}$

posite. Figure 9 shows the comparison of discharge capacity at the tenth cycle at a current density of $0.2 \mathrm{C}$ for the samples with different $\mathrm{S}$ loading. It can be seen that the discharge capacity increases initially, and a high value of $805 \mathrm{mAh} \cdot \mathrm{g}^{-1}$ was delivered after ten cycles at a $\mathrm{S}$ loading of $3.25 \mathrm{mg} \cdot \mathrm{cm}^{-2}$. However, as the loading increased further, the capacity value reduced significantly. For example, at a high $\mathrm{S}$ loading of $4.75 \mathrm{mg} \cdot \mathrm{cm}^{-2}$, the material could deliver a capacity of $723 \mathrm{mAh} \cdot \mathrm{g}^{-1}$. This capacity decrease could be due to a reduced conductivity of the electrodes related to the excessive content of S. Furthermore, 


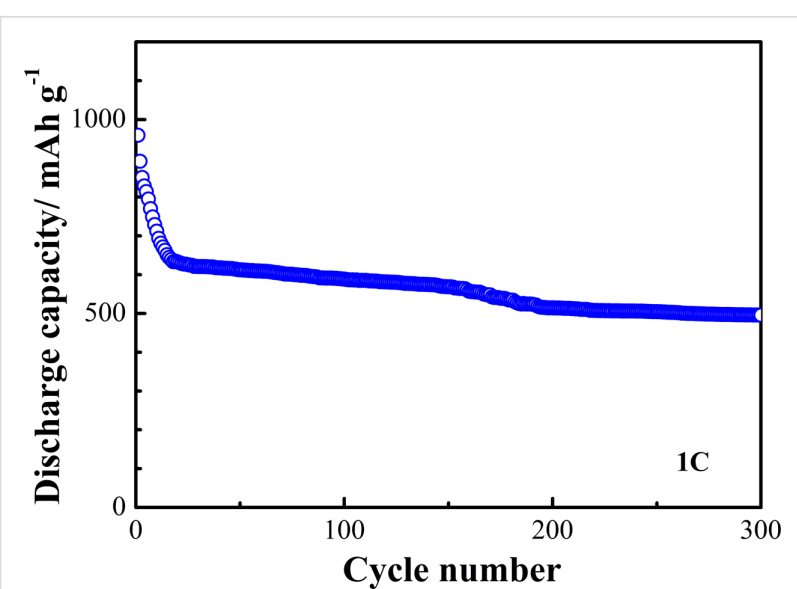

Figure 8: Long-term cycle life of the S/ZnO@NCNT cathode at 1C.

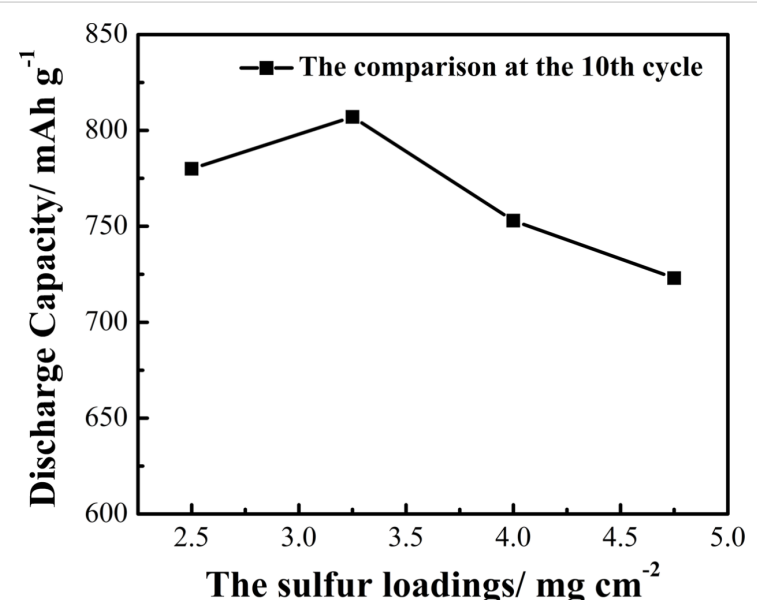

Figure 9: The performance comparison of S/ZnO@NCNT electrodes with sulfur loadings of $2.5,3.25,4.0$ and $4.75 \mathrm{mg} \cdot \mathrm{cm}^{-2}$ at the $10 \mathrm{th}$ cycle at $0.2 \mathrm{C}$.

sulfur tends to agglomerate, and this negatively affects the cycle performance of the cell as well.

The rate capability of the $\mathrm{S} / \mathrm{ZnO} @ \mathrm{NCNT}$ cathode at rates from $0.1 \mathrm{C}$ to $2 \mathrm{C}$ was studied as well (Figure 10 ). Although the discharge capacity of the S/ZnO@NCNT cathode gradually decreases with the cycling rate, at each individual rate from $0.2 \mathrm{C}$ to $2 \mathrm{C}$, the composite cathode exhibit a relatively steady reversible capacity. At $2 \mathrm{C}$, a reversible capacity of $650 \mathrm{mAh} \cdot \mathrm{g}^{-1}$ was reached. When the current rate was changed back to $0.1 \mathrm{C}$, the capacity of the $\mathrm{S} / \mathrm{ZnO} @ \mathrm{NCNT}$ cathode recovered to $822 \mathrm{mAh} \cdot \mathrm{g}^{-1}$. This indicates that the as-prepared $\mathrm{S} / \mathrm{ZnO} @ \mathrm{NCNT}$ composite is very stable and can tolerate the abusive condition of high-rate $\mathrm{Li}$ ion insertion and deletion. In addition to a strong $\mathrm{S}$ "confinement" effect of the active $\mathrm{ZnO}$ surface, this might also be attributed to the NCNT network and the small size of $\mathrm{ZnO}$ nanoparticles $(6.2 \mathrm{~nm})$ in the composite,

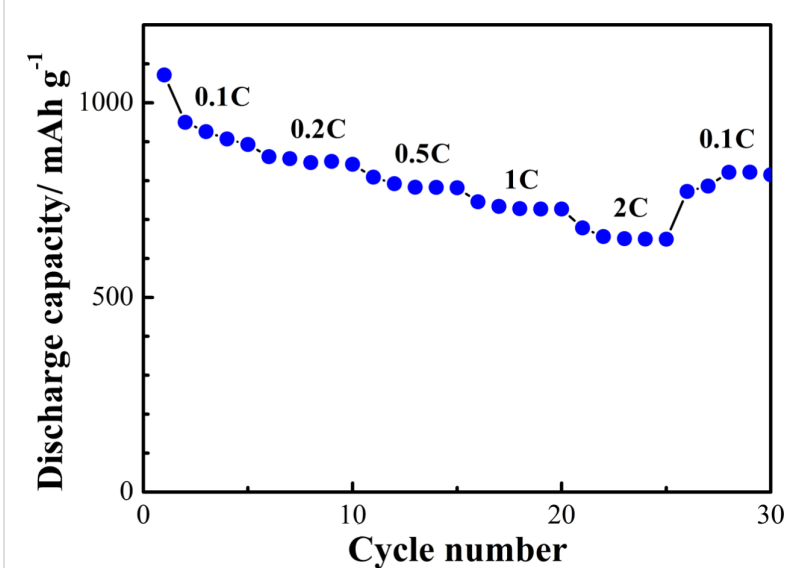

Figure 10: Rate capability of the S/ZnO@NCNT composite cathode.

which both enhanced charge transfer and conductivity. Along with this, the NCNT network provides a large micro-scaffold in the $\mathrm{S} / \mathrm{ZnO} @ \mathrm{NCNT}$ composite to accommodate $\mathrm{S}$ and Li ions, and, therefore, to buffer the volume expansion/shrinkage caused by the fast $\mathrm{Li}$ insertion/deletion. Moreover, small size $\mathrm{ZnO}$ nanoparticles provide abundant active sites for $\mathrm{Li}$ ion insertion and deletion and can also "buffer" the structural damage of the composite. In our previous work [13], it has been demonstrated that NCNT network and ZnO nanoparticles in ZnO@NCNT have these advantageous properties for the use in Li-ion batteries. The discharge/charge potential profiles of the cell at various rates also confirm the excellent stability of the $\mathrm{S} / \mathrm{ZnO} @ \mathrm{NCNT}$ composite cathode (Figure 11). The results show that there is only a slightly fading of the potential plateaus with increasing rate. More importantly, it can be observed that there is only a small polarization of the electrode, which demonstrates highly reversible features of Li ion insertion/deletion in the S/ZnO@NCNT composite at various cycling rates.

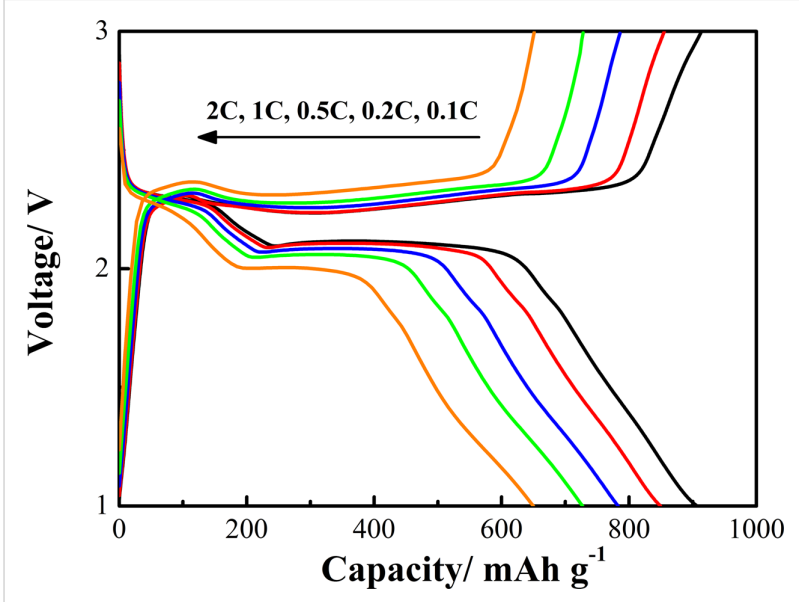

Figure 11: Discharge/charge voltage profiles of S/ZnO@NCNT composite cathode at various rates. 
Table 1 compares the performance data reported for $\mathrm{Li} / \mathrm{S}$ batteries with the results of this work. The S/ZnO@NCNT electrode prepared in this work displays superior electrochemical performance, even with the higher sulfur loadings. The S/INC composite reported in our previous research work is based on INC, which has a high specific surface area and a large number of mesopores. Unlike ZnO@NCNT reported in the current work, which binds sulfur to the surface, INC encapsulates sulfur inside the pore structure and therefore provides a higher specific capacity. However, INC does not have $\mathrm{ZnO}$-rich active sites and is prone to damage upon the intercalation/deintercalation of $\mathrm{Li}$ ions, so the cycle performance of this system is not as good as that of $\mathrm{S} / \mathrm{ZnO} @ \mathrm{NCNT}$. Therefore, the results of this study demonstrate that the NCNT core and the smaller size of the $\mathrm{ZnO}$ nanoparticles are effective to remarkably improve the electrochemical performance of the S/ZnO@NCNT electrode.

\section{Conclusion}

Nitrogen-doped carbon nanotubes coated with zinc oxide (ZnO@NCNT) were successfully prepared via a sol-gel synthetic route. They exhibit a unique ability to absorb polysulfides and, thus, to improve electrochemical properties of a $\mathrm{S}$ cathode. The S/ZnO@NCNT cathode has shown excellent cycling stability and rate capability in $\mathrm{Li} / \mathrm{S}$ batteries. This enhanced electrochemical performance originates from its active $\mathrm{ZnO}$ surfaces, which can provide a strong bonding capability for $\mathrm{S}$ atoms. Moreover, it is believed that the large micro-scaffold in the NCNT network not only improves the conductivity of the composite, but also facilitates the modulation of $\mathrm{S}$ and $\mathrm{Li}$ ions, buffering the volume expansion/shrinkage caused by the fast $\mathrm{Li}$ insertion/deletion.

\section{Experimental}

\section{Preparation of ZnO@NCNT composite}

The ZnO@NCNT composite was synthesized by sol-gel synthesis [13,34]. In a typical synthesis, $7.717 \mathrm{~g}$ zinc acetate $\left(\mathrm{Zn}\left(\mathrm{CH}_{3} \mathrm{COO}\right)_{2}, \geq 99 \%\right)$ was dissolved in $260 \mathrm{~mL}$ ethanol
$\left(\mathrm{C}_{2} \mathrm{H}_{5} \mathrm{OH}, \geq 99.7 \%\right)$. Meanwhile, $1.508 \mathrm{~g}$ lithium hydroxide $\left(\mathrm{LiOH} \cdot \mathrm{H}_{2} \mathrm{O}, \geq 90 \%\right.$ ) was dissolved in another $260 \mathrm{~mL}$ of ethanol. The molar ratio of $\mathrm{Zn}\left(\mathrm{CH}_{3} \mathrm{COO}\right)_{2}$ and $\mathrm{LiOH} \cdot \mathrm{H}_{2} \mathrm{O}$ was 1.3:1. These solutions were magnetically stirred until the reagents were completely dissolved. After that, the $\mathrm{LiOH}$ and $\mathrm{Zn}\left(\mathrm{CH}_{3} \mathrm{COO}\right)_{2}$ solutions were mixed together and stirred for $20 \mathrm{~min}$. Then, $0.17 \mathrm{~g}$ of nitrogen-doped multi-walled carbon nanotubes (NCNT, N content of $2.98 \%$, Beijing Dk Nano Technology) was added to the above mixture solution under magnetic stirring for a week. The resulting black sol product was centrifuged and washed several times with deionized water and ethanol, then dried in a vacuum oven at $70{ }^{\circ} \mathrm{C}$ for $12 \mathrm{~h}$ to obtain the $\mathrm{ZnO} @ \mathrm{NCNT}$ composite.

\section{Preparation of S/ZnO@NCNT composite}

The as-prepared ZnO@NCNT was mixed with nano-sulfur in a molar ratio of $1: 3$ by ball-milling at $350 \mathrm{~min}^{-1}$ for $3 \mathrm{~h}$ to obtain the sulfur composite precursor. The S/ZnO@NCNT composite was obtained by heating the precursor at $155^{\circ} \mathrm{C}$ for $10 \mathrm{~h}$, in argon flow with a heating rate of $5{ }^{\circ} \mathrm{C} \cdot \mathrm{min}^{-1}$. The sulfur-doping method was described in our previous study [33].

\section{Materials characterization}

Powder X-ray diffraction (XRD, SmartLab, Rigaku Corporation) with $\mathrm{Cu} \mathrm{Ka}$ radiation was used to analyze the crystal structure of the S/ZnO@NCNT sample. The chemical status and elemental compositions of the sample were investigated by X-ray photoelectron spectroscopy (XPS, Shimadzu Axis Ultra). Scanning electron microscopy (SEM) images were collected on a Hitachi S4800 scanning electron microscope. High-resolution transmission electron microscopy (HRTEM) images were recorded with a JEOL JEM-2100F transmission electron microscope. The elements distribution images were detected by using TEM at $160 \mathrm{kV}$. Thermogravimetric analysis (TA Universal Analysis 2000, SDT2960) was conducted from room temperature to $500{ }^{\circ} \mathrm{C}$ with a heating rate of $10{ }^{\circ} \mathrm{C} \cdot \mathrm{min}^{-1}$ in nitrogen.

\begin{tabular}{|c|c|c|c|c|c|c|}
\hline material & $\begin{array}{l}\text { reversible capacity } \\
\left(\mathrm{mAh} \cdot \mathrm{g}^{-1}\right)\end{array}$ & cycle number & current density & $\begin{array}{l}\text { applied potential } \\
\text { range }(\mathrm{V})\end{array}$ & $\begin{array}{l}\text { sulfur loading } \\
\left(\mathrm{mg} \cdot \mathrm{cm}^{-2}\right)\end{array}$ & reference \\
\hline MWNT@ZIF-S & 380 & 25 & $0.1 \mathrm{C}$ & $1.0-3.0$ & 0.6 & [27] \\
\hline Al-ZnO@c/S & 544 & 300 & $0.5 \mathrm{C}$ & $1.8-2.6$ & 3.3 & [28] \\
\hline S/PPy & 503 & 100 & $0.1 \mathrm{C}$ & $1.5-3$ & 4 & {$[26]$} \\
\hline $\mathrm{Fe}_{2} \mathrm{O}_{3} / \mathrm{S}$ & 442.3 & 100 & $0.5 \mathrm{C}$ & $1.0-3.0$ & 0.56 & [29] \\
\hline $\mathrm{A}-\mathrm{TiO}_{2-\mathrm{x}} \mathrm{NSs}-\mathrm{S}$ & 610 & 100 & $0.1 \mathrm{C}$ & $1.7-2.8$ & 1.17 & [30] \\
\hline Meso-C/S & 470.2 & 300 & $0.5 \mathrm{C}$ & $1.7-2.7$ & 2.0 & [31] \\
\hline S/NGC & 572 & 100 & $0.2 \mathrm{C}$ & $1.7-2.8$ & 3.4 & [32] \\
\hline S/INC & 702 & 50 & $0.1 \mathrm{C}$ & $1.0-3.0$ & 3.0 & [33] \\
\hline S/ZnO@NCNT & 665 & 100 & $0.2 \mathrm{C}$ & $1.0-3.0$ & 3.25 & this work \\
\hline
\end{tabular}




\section{Electrochemical measurements}

The cathode was fabricated by mixing $80 \mathrm{wt} \%$ as-prepared S/ZnO@NCNT composite, 10 wt \% acetylene black and $10 \mathrm{wt} \%$ polyvinylidene fluoride (PVDF) in $\mathrm{N}$-methyl-2-pyrrolidone (NMP). The resulting homogeneous slurry was coated on nickel foam and subsequently dried at $75^{\circ} \mathrm{C}$ overnight. Metallic lithium foil served as a counter and reference electrode, and micro-porous polypropylene film (Cellgard 2300) was used as a separator. The electrolyte was $1 \mathrm{M}$ lithium bistrifluoromethanesulfonamide (LiTFSI) in tetraethylene glycol dimethyl ether as a solvent. The CR2025 coin cells assembly was carried out in an argon-filled glovebox (Mikrouna, Shanghai). The charge/discharge cycling performances was investigated using a battery testing system (Neware, Shenzhen) in the potential range of $1-3 \mathrm{~V}$ vs $\mathrm{Li} / \mathrm{Li}^{+}$.

\section{Acknowledgements}

The authors acknowledge the financial support from the National Natural Science Foundation of China (Grant No. 21406052), Scientific Research Foundation for Selected Overseas Chinese Scholars, Ministry of Human Resources and Social Security of China (Grant No. CG2015003002) and the Program for the Outstanding Young Talents of Hebei Province.

\section{References}

1. Yuan, G.; Zhao, Y.; Jin, H.; Bakenov, Z. Ionics 2016, 22, 1819-1827. doi:10.1007/s11581-016-1729-7

2. Zhang, Y.; Zhao, Y.; Konarov, A.; Gosselink, D.; Soboleski, H. G.; Chen, P. J. Power Sources 2013, 241, 517-521. doi:10.1016/j.jpowsour.2013.05.005

3. Zhang, Z.; Jing, H.-K.; Liu, S.; Li, G.-R.; Gao, X.-P. J. Mater. Chem. A 2015, 3, 6827-6834. doi:10.1039/C4TA07183B

4. Sun, Q.; Yadegari, H.; Banis, M. N.; Liu, J.; Xiao, B.; Wang, B.; Lawes, S.; Li, X.; Li, R.; Sun, X. Nano Energy 2015, 12, 698-708. doi:10.1016/j.nanoen.2015.01.018

5. Qiu, Y.; Li, W.; Zhao, W.; Li, G.; Hou, Y.; Liu, M.; Zhou, L.; Ye, F.; Li, H.; Wei, Z.; Yang, S.; Duan, W.; Ye, Y.; Guo, J.; Zhang, Y. Nano Lett. 2014, 14, 4821. doi:10.1021/nl5020475

6. Xiao, Z.; Yang, Z.; Wang, L.; Nie, H.; Zhong, M.; Lai, Q.; Xu, X.; Zhang, L.; Huang, S. Adv. Mater. 2015, 27, 2891-2898. doi:10.1002/adma.201405637

7. Gopi, C. V. V. M.; Venkataharitha, M.; Lee, Y.-S.; Kim, H.-J. J. Mater. Chem. A 2016, 4, 8161-8171. doi:10.1039/C6TA02415G

8. Rehman, S.; Tang, T.; Ali, Z.; Huang, X.; Hou, Y. Small 2017, 13, 1700087. doi:10.1002/smll.201700087

9. Rehman, S.; Guo, S.; Hou, Y. Adv. Mater. 2016, 28, 3166. doi:10.1002/adma.201670111

10. Li, Y.; Cai, Q.; Lei, W.; Li, Q.; Xiang, P.; Gao, B.; Huo, K.; Chu, P. K. ACS Appl. Mater. Interfaces 2016, 8, 23784-23792. doi:10.1021/acsami.6b09479

11. Li, Z.; Zhang, J.; Lou, X. W. Angew. Chem., Int. Ed. 2015, 54, 12886-12890. doi:10.1002/anie.201506972

12. Zhou, W.; Xiao, X.; Cai, M.; Yang, L. Nano Lett. 2014, 14, 5250. doi:10.1021/nl502238b
13. Li, H.; Liu, Z.; Yang, S.; Zhao, Y.; Feng, Y.; Bakenov, Z.; Zhang, C.; Yin, F. Materials 2017, 10, 1102. doi:10.3390/ma10101102

14. Zhang, Y.; Wei, Y.; Li, H.; Zhao, Y.; Yin, F.; Wang, X. Mater. Lett. 2016, 184, 235-238. doi:10.1016/j.matlet.2016.08.017

15. Li, H.; Wei, Y.; Zhang, Y.; Yin, F.; Zhang, C.; Wang, G.; Zhumabay, B. lonics 2016, 22, 1387-1393. doi:10.1007/s11581-016-1661-X

16. Zhao, Y.; Yin, F.; Zhang, Y.; Zhang, C.; Mentbayeva, A.; Umirov, N.; Hong, X.; Zhumabay, B. Nanoscale Res. Lett. 2015, 10, 450. doi:10.1186/s11671-015-1152-4

17. Zhang, J.; Gu, P.; Xu, J.; Xue, H.; Pang, H. Nanoscale 2016, 8, 18578. doi:10.1039/C6NR07207K

18. Le, A. V.; Wang, M.; Shi, Y.; Noelle, D.; Qiao, Y.; Lu, W. J. Appl. Phys. 2015, 118, 968. doi:10.1063/1.4929647

19. Gandhi, R. R.; Gowri, S.; Suresh, J.; Sundrarajan, M. J. Mater. Sci. Technol. 2013, 29, 533-538. doi:10.1016/j.jmst.2013.03.007

20. Meyer, B.; Marx, D. Phys. Rev. B 2003, 67, 039902. doi:10.1103/PhysRevB.67.039902

21. Brill, G.; Chen, Y.; Dhar, N. K.; Singh, R. J. Electron. Mater. 2003, 32, 717-722. doi:10.1007/s11664-003-0058-6

22. Siriwardane, R. V.; Poston, J. A. Appl. Surf. Sci. 1990, 45, 131-139. doi:10.1016/0169-4332(90)90063-6

23. Fantauzzi, M.; Elsener, B.; Atzei, D.; Rigoldi, A.; Rossi, A. RSC Adv. 2015, 5, 75953-75963. doi:10.1039/C5RA14915K

24. Moon, J.; An, J.; Sim, U.; Cho, S.-P.; Kang, J.-H.; Chung, C.; Seo, J. H.; Lee, J.; Nam, K. T.; Hong, B. H. Adv. Mater. 2014, 26, 3501-3505. doi:10.1002/adma.201306287

25. Chen, C.; Wang, L.; Li, F.; Ling, L. Mater. Chem. Phys. 2014, 146, 531-537. doi:10.1016/j.matchemphys.2014.04.011

26. Yin, F.; Liu, X.; Zhang, Y.; Zhao, Y.; Menbayeva, A.; Bakenov, Z.; Wang, X. Solid State Sci. 2017, 66, 44-49. doi:10.1016/j.solidstatesciences.2017.02.009

27. Yue, Y.; Guo, B.; Qiao, Z. A.; Fulvio, P. F.; Chen, J.; Binder, A. J.; Tian, C.; Dai, S. Microporous Mesoporous Mater. 2014, 198, 139-143. doi:10.1016/j.micromeso.2014.07.026

28. Kong, Y.; Luo, J.; Jin, C.; Yuan, H.; Sheng, O.; Zhang, L.; Fang, C.; Zhang, W.; Huang, H.; Xia, Y.; Liang, C.; Zhang, J.; Gan, Y.; Tao, W. Nano Res. 2018, 11, 477-489. doi:10.1007/s12274-017-1655-7

29. Zhao, C.; Shen, C.; Xin, F.; Sun, Z.; Han, W. Mater. Lett. 2014, 137, 52-55. doi:10.1016/j.matlet.2014.08.115

30. Wang, H.-C.; Fan, C.-Y.; Zeng, Y.-P.; Zhang, X.-H.; Li, W.-H.; Liu, S.-Y.; Sun, H.-Z.; Zhang, J.-P.; Sun, L.-N.; Wu, X.-L. Chem. - Eur. J. 2017, 23, 9666-9673. doi:10.1002/chem.201701580

31. Bao, W.; Su, D.; Zhang, W.; Guo, X.; Wang, G. Adv. Funct. Mater. 2016, 26, 8746-8756. doi:10.1002/adfm.201603704

32. Vinayan, B. P.; Diemant, T.; Lin, X.-M.; Cambaz, M. A.; Golla-Schindler, U.; Kaiser, U.; Behm, R. J.; Fichtner, M. Adv. Mater. Interfaces 2016, 3, 1600372. doi:10.1002/admi.201600372

33. Li, H.; Wang, Z.; Zhang, Y.; Wang, X.; Zhao, Y.; Maximov, M. Y.; Ji, P.; Yin, F. Russ. J. Appl. Chem. 2016, 89, 1336-1340. doi:10.1134/S107042721608019X

34. Li, H.; Wei, Y.; Zhang, Y.; Zhang, C.; Wang, G.; Zhao, Y.; Yin, F.; Bakenov, Z. Ceram. Int. 2016, 42, 12371-12377. doi:10.1016/j.ceramint.2016.05.010 


\section{License and Terms}

This is an Open Access article under the terms of the Creative Commons Attribution License

(http://creativecommons.org/licenses/by/4.0), which permits unrestricted use, distribution, and reproduction in any medium, provided the original work is properly cited.

The license is subject to the Beilstein Journal of Nanotechnology terms and conditions:

(https://www.beilstein-journals.org/bjnano)

The definitive version of this article is the electronic one which can be found at:

doi:10.3762/bjnano.9.159 